Revista Bioética

\title{
ATUALIZAÇÃO
}

\section{Desafios e conflitos bioéticos da covid-19: contexto da saúde global}

Norton Nohama ${ }^{1}$, Jefferson Soares da Silva ${ }^{2}$, Daiane Priscila Simão-Silva ${ }^{3}$

1. Universidade Federal do Paraná, Curitiba/PR, Brasil. 2. Genitore Guarapuava, Guarapuava/PR, Brasil. 3. Instituto de Pesquisa do Câncer, Guarapuava/PR, Brasil.

\section{Resumo}

A pandemia desencadeada pela covid-19, imersa em muitas incertezas, suscita uma série de conflitos éticos. 0 objetivo deste artigo é refletir sobre esses conflitos e sobre os distintos interesses envolvidos no atual cenário. 0 horizonte da análise crítica é a bioética global, e o foco do estudo é o Brasil, onde os problemas de saúde decorrentes da covid-19 não têm sido abordados de forma integrada à diplomacia internacional. No país, a oposição simplista entre saúde e economia tem servido de base para decisões estratégicas e medidas de contenção do vírus. No entanto, as variáveis a se considerar são múltiplas, e é necessário um balizador ético, como a responsabilidade dos agentes políticos quanto ao desfecho de suas decisões.

Palavras-chave: Responsabilidade pela informação. Coronavírus. Bioética. Risco. Precaução. Diplomacia. Conhecimento.

\section{Resumen}

\section{Desafíos y conflictos bioéticos de la covid-19: contexto de salud global}

La pandemia desencadenada por la covid-19, inmersa en muchas incertidumbres, genera una serie de conflictos éticos. Este artículo tiene como objetivo contribuir para la reflexión sobre estos conflictos y sobre los distintos intereses implicados en el escenario actual. El horizonte del análisis crítico es la bioética global, y el estudio se concentra en Brasil, donde los problemas de salud derivados de la covid-19 no han sido abordados de forma integrada a la diplomacia internacional. En este país, la oposición simplista entre salud y economía ha servido de base para decisiones estratégicas y medidas de contención del virus. Sin embargo, múltiples son las variables que se deben tener en cuenta, y son necesarias referencias éticas, como la responsabilidad de los agentes políticos en cuanto al desenlace de sus decisiones.

Palabras clave: Deber de advertencia. Coronavirus. Bioética. Riesgo. Precaución. Diplomacia. Conocimiento.

\section{Abstract}

\section{Covid-19 bioethical challenges and conflicts: global health context}

Characterized by extreme uncertainty, the Covid-19 outbreak raises important ethical conflicts. In this article, we reflect on these conflicts and the different interests involved in the current scenario. Our critical analysis is based on global bioethics, and focused on Brazil, where public health issues have not been properly integrated with international diplomacy. The simplistic opposition between health and economy has been used as a decisionmaking strategy and to establish measures to control the virus. However, there are several variables in this context, and an ethical guideline becomes necessary, especially for the decisions made by politicians in the country. Keywords: Duty to warn. Coronavirus. Bioethics. Risk. Precaution. Diplomacy. Knowledge. 
O espírito da responsabilidade rejeita o veredito prematuro da fatalidade por ter assumido o rumo "da história" (...). Ao princípio esperança, contrapomos o princípio responsabilidade, e não o princípio medo. Mas, certamente, o medo pertence à responsabilidade, tanto quanto a esperança ${ }^{1}$.

Este primeiro quarto de século já tem marca própria: a pandemia de covid-19, causada pelo vírus Sars-CoV-2, que começou no final de 2019 na China e rapidamente se alastrou pelo globo, com especial intensidade na Itália, Espanha, no Reino Unido e nos Estados Unidos, onde o número de contaminados e vítimas fatais forma cenário dramático ${ }^{2}$. Os indicadores do último bimestre de 2020 são surpreendentes, e Estados Unidos, Índia e Brasil se destacam por concentrar, juntos, quase metade de todos os casos confirmados no mundo (13.082.877, 9.431.691 e 6.290.272, respectivamente, de um total de 62.363 .527 casos em 30 de novembro de 2020). Óbitos registrados seguem itinerário semelhante, sendo que os mesmos países concentram $39,4 \%$ do total global. O continente europeu vive segunda onda pandêmica, podendo ser seguido pelo Brasil nos próximos meses, e Estados Unidos e Índia assistem ao contágio se espalhar pelo seu interior ${ }^{3}$.

Até então, as discussões no âmbito da saúde global estavam centradas na transição epidemiológica das doenças infectocontagiosas para as crônicas e degenerativas, mas o cenário atual incorpora situações e especificidades nacionais e disputas geopolíticas que desafiam a gestão dos problemas e de seus efeitos. Pela amplitude de reflexos sobre a sociedade, inclusive em seu modo de existir, a pandemia exige ações e intervenções articuladas, compartilhadas e coordenadas globalmente. Neste cenário, as decisões de gestores em saúde e governantes vêm produzindo efeitos muito diversos e contrastantes, que obrigam à reflexão crítica sobre as causas de tais disparidades.

Cumpre papel crucial nesta crítica, de um lado, a reflexão acerca da fundamentação científica da tomada de decisões e, de outro, a justificativa ética que a sustenta, o que faz emergir perspectivas conflitantes em relação ao melhor curso de ação. Tais decisões, emanadas dos mais altos níveis governamentais, têm efeitos diretos e imediatos no complexo cotidiano das unidades de saúde e na relação médico-paciente - cujo característico pragmatismo conduz a decisões baseadas em normativas e recomendações de natureza clínica ou deontológica.

Com efeito, um olhar mais detido sobres estas decisões parece sugerir dois universos, o individual e o coletivo, que tratam da mesma realidade sob perspectivas diversas, partindo de princípios frequentemente distintos e inconciliáveis: aqueles dos gestores da pandemia e aqueles dos profissionais de saúde. Este ensaio reflete sobre esses dois universos, buscando identificar seu balizamento ético e se são sustentáveis sob o viés analítico da ética da responsabilidade de Hans Jonas ${ }^{4} \mathrm{e}$ da bioética global de Van Rensselaer Potter ${ }^{5}$. O referencial para a discussão será o Brasil, cujo contexto atual, aliado à idiossincrasia de seus gestores públicos, apresenta aspectos singulares para o debate.

\section{A pandemia}

O Sars-CoV-2 é o agente viral causador do que se denominou "coronavirus disease 2019" (covid-19) ${ }^{6}$. Seu material genético é composto basicamente por 30 mil genes organizados em RNA envelopado ${ }^{7-11}$. A família de coronavírus é conhecida por causar doenças de gravidade abundantemente variada. A primeira epidemia causada por esse tipo de vírus, de síndrome respiratória aguda grave (Sars), foi registrada em 2003, na Ásia. Em 2012, outro coronavírus se manifestou na Arábia Saudita, com a síndrome respiratória do Oriente Médio (Mers) ${ }^{12}$. Além destas três variantes, outras quatro (HKU1, NL63, OC43 e 229E) são conhecidas por causar doenças consideradas de baixa gravidade em humanos ${ }^{7,11,13}$.

O primeiro caso de infecção por Sars-CoV-2 de que se tem registro ocorreu em Wuhan, província de Hubei, na China, onde um paciente, exposto no mercado molhado da cidade, apresentou quadro clínico de pneumonia aguda grave até então desconhecida $^{6}$. Alguns animais, como o morcego (Rhinolophus affinis) e o pangolim-malaio (Manis javanica), foram considerados possíveis vetores originais de transmissão para humanos, em razão da proximidade genômica dos coronavírus encontrados nestas espécies e o que está causando a covid-197,8.

Estudos mostram ampla similaridade do genoma de todas as linhagens mapeadas no mundo, sugerindo que um único contágio animal-humano tenha originado a pandemia 7,8,14. Desde o início da disseminação, questões que envolvem biossegurança e bioproteção, incluindo governança, assumiram especial importância. Embora o Sars-CoV-2 tenha sido classificado em grau de risco 2, sua alta transmissibilidade e virulência demonstram que é necessário adotar níveis de biossegurança mais elevados, em especial para os profissionais de saúde, entre os quais o número de infecções e óbitos tem sido bastante expressivo ${ }^{15,16}$. Como até o momento não há vacina nem tratamento contra Sars-CoV-2, pacientes em estado clínico grave têm recebido medicamentos 
para atenuar sintomas, além de sedação, indução de coma e, quando necessário, suporte respiratório mecânico, na expectativa de que o sistema imunológico responda e consiga debelar o processo viral ${ }^{17,18}$.

Os efeitos em longo prazo em pacientes que foram internados em unidade de terapia intensiva (UTI) são desafio ainda pouco conhecido. No entanto, a experiência em medicina intensivista com outras moléstias permite algumas previsões. $\mathrm{O}$ uso de ventiladores leva parte dos pacientes a desenvolver síndrome do desconforto respiratório agudo, atrofia e fraqueza muscular ${ }^{19}$. De acordo com Servick, suspeita-se que muitos pacientes de covid-19 que precisam de ventilador nunca se recuperam. Embora taxas de sobrevivência variem entre estudos e países, um relatório do Centro Nacional de Pesquisa e Auditoria em Cuidados Intensivos de Londres descobriu que $67 \%$ dos pacientes de covid-19 da Inglaterra, do País de Gales e da Irlanda do Norte que receberam "suporte respiratório avançado" morreram. Um estudo em um grupo menor de pacientes na China descobriu que apenas $14 \%$ sobreviveram depois de usar ventilador ${ }^{20}$.

Ainda que os dados das pesquisas em andamento contenham inconsistências - e é natural que isso aconteça, dado que o conhecimento está sendo construído enquanto a epidemia avança -, quatro aspectos parecem certos: 1) sem acesso a recursos de terapia intensiva os pacientes graves não têm chance de sobreviver; 2) o acesso à terapia intensiva não é garantia de recuperação, e parte substancial dos pacientes ainda assim não sobrevive; 3 ) o grau de sofrimento físico e psíquico dos pacientes em estado grave é muito elevado; e 4) a sobrevivência a quadros graves não é isenta de sequelas, algumas prolongadas e de difícil superação.

A alta taxa de propagação do vírus, favorecida pela transmissão por via aérea, pelo contato da mucosa oronasal e, principalmente, pelo alto nível de virulência resultante da facilidade de atuação sobre o receptor celular (a enzima ACE2), tem provocado em todos os países afetados quadro relativamente comum: altos índices de mortalidade concentrados em período muito curto de tempo, com curvas pandêmicas imprevisíveis ${ }^{21-24}$.

\section{Estratégias de enfrentamento no Brasil para o problema global}

Diversos aspectos, como comportamento e dinâmica evolutiva do vírus sobre cada grupo populacional, características ambientais, genéticas e epigenéticas dos hospedeiros humanos, bem como fatores culturais e socioeconômicos tornam difícil prever a evolução epidemiológica da covid-19 em cada país. No entanto, as estratégias de tomada de decisão na área da saúde devem ser baseadas em evidências, e o Brasil poderia ter se beneficiado com as informações e o conhecimento acumulados pelos países que já vinham enfrentando a epidemia.

De forma geral, duas abordagens aparentemente opostas estão sendo amplamente discutidas, em especial no Brasil. A primeira visa reduzir a velocidade de disseminação do vírus pelo chamado "achatamento da curva epidêmica", objetivando impedir que a demanda por leitos de UTI ultrapasse a capacidade instalada em cada região, evitando óbitos decorrentes do colapso do sistema de saúde e da insuficiência de recursos. A segunda abordagem permite e até estimula a ampla disseminação e contágio do vírus, com a finalidade de atingir rapidamente altas taxas de autoimunização populacional, visando alterar a cadeia de transmissão do agente e, com isso, debelar a epidemia por meio da chamada "imunidade de rebanho".

Em tese, esta última abordagem teria como efeito secundário evitar novos surtos da doença. No entanto, tal opção não está livre de riscos, como o que diz respeito à imprevisibilidade da mutação do Sars-CoV-2 e possíveis alterações em seus mecanismos moleculares internos, que poderiam aumentar sua virulência e letalidade. Zhu e colaboradores ${ }^{6}$, por exemplo, sinalizam que esta pode ser doença sazonal com a qual a humanidade terá que conviver nos próximos anos. Assim, sob o princípio da precaução de Jonas ${ }^{4}$, é interessante discutir se as duas estratégias são moralmente aceitáveis, considerando se podem ou não ser estendidas para todas as atividades humanas com efeitos imediatos ou futuros incertos para a saúde humana.

Paralelo no mínimo interessante e até pedagógico pode ser feito, por exemplo, com a histórica Peste Negra, que se disseminou em três grandes eventos pandêmicos na era cristã. O primeiro ciclo, no século VI, resultou em 100 milhões de mortes; o segundo, no século XIV, dizimou $40 \%$ da população europeia; e o terceiro, no século XIX, se propagou da China para diversos países ${ }^{25}$. Segundo Barros, relevante estudo comparativo do genoma das cepas IP32953 (Y. pseudotuberculosis) e CO92 (Y. pestis) revelou aspectos do processo evolutivo que transformou um ancestral enteropatogênico em dois patógenos com manifestações clínicas distintas (...) Estes resultados promovem um exemplo de como uma espécie, altamente virulenta, pode surgir de uma espécie pouco virulenta ${ }^{26}$. 
Se, com efeito, este é exemplo clássico de evolução viral de resultado desastroso para a espécie humana, o momento atual recomenda, por precaução, refletir se estamos diante de novo evento de proporções igualmente trágicas. Alguns especialistas vão além, afirmando que evento similar é iminente, só não se sabe ainda quando acontecerá ${ }^{27}$.

\section{Doença X: um alerta global}

A criação da Organização Mundial da Saúde (OMS), em 1948, foi importante marco na governança da saúde global. A despeito das dificuldades e limitações históricas, é necessário reconhecer que as iniciativas recentes da organização, no sentido de estimular e orientar a comunidade científica em um grande esforço conjunto, são o mais importante alento no desenvolvimento de pesquisas em busca de medicamentos e vacinas para o combate ao Sars-CoV-2. Um olhar retrospectivo sobre a atuação da OMS ajuda a compreender a importância da ação global em saúde e a necessidade de adesão incondicional e comprometida de todos os Estados-membros com a proteção coletiva de toda a humanidade e biosfera.

Respondendo ao relatório de um painel de especialistas chamado para avaliar a resposta da organização à epidemia causada pelo vírus ebola ${ }^{28}$, o secretário-geral da OMS apontou, em 2015, a necessidade de acelerar os processos de pesquisa e desenvolvimento (P\&D) a fim de capacitar o mundo para lidar com epidemias e emergências em saúde ${ }^{29}$. Pouco depois, a organização publicou a primeira lista de agentes patogênicos prioritários para P\&D. Atualizada em 2017 e 2018, ela incluía as duas síndromes causadas por coronavírus até então conhecidas (Mers e Sars), além da febre hemorrágica da Crimeia-Congo; doença do vírus ebola e febre hemorrágica de Marburgo; febre de Lassa; (...) infecção pelo vírus Nipah e doenças relacionadas aos henipavírus; febre do vale do Rift; vírus zika; [e] doença $X^{27}$.

$A$ "doença $X$ " representava o entendimento da OMS de que poderia surgir uma pandemia causada por patógeno até então desconhecido ${ }^{27}$. Nessa perspectiva, o atual Sars-CoV-2 tanto pode ser enquadrado na categoria dos coronavírus citada na lista como na categoria "doença X". No momento, a preocupação demonstrada pela OMS assume contornos particularmente relevantes, na medida em que, desde então, não se percebem sinais claros de que o apelo da entidade tenha repercutido entre governos, agências de fomento à pesquisa, empresas de biotecnologia e indústria farmacêutica.
Outro aspecto singularmente expressivo para o momento atual, apontado pelo citado painel de especialistas, é que a crise do ebola não só expôs as falhas organizacionais no funcionamento da OMS, mas também demonstrou limitações do Regulamento Sanitário Internacional ${ }^{30}$. O relatório conclui que a OMS não tem capacidade ou cultura operacional para proporcionar uma plena resposta de emergência de saúde pública ${ }^{31}$, ficando evidente também que a agência sofre com a falta de compromisso político e financeiro de seus Estados-membros.

Além disso, os especialistas apontaram que, se as recomendações feitas em 2009 pelo Comitê de Revisão sobre a pandemia de H1N1 tivessem sido consideradas, o mundo teria enfrentado a crise do ebola em condições mais adequadas ${ }^{28}$. Ou seja, decorridas quase duas décadas desde a primeira epidemia por Sars, em 2003, passando pela epidemia de H1N1 em 2009, Mers em 2012 e ebola em 2013, chegamos a 2020 em um cenário que mostra como governantes têm ignorado os alertas da OMS e da comunidade científica.

Surpreendentemente, a primeira vez que o Conselho de Segurança da Organização das Nações Unidas (ONU) se reuniu para tratar de um problema de saúde foi para discutir a epidemia do ebola, em $2014^{32}$. No entanto, o citado relatório do painel de especialistas deixou claro que essa reunião não foi capaz de alterar substancialmente a realidade trágica da epidemia ${ }^{28}$. A primeira manifestação do Conselho sobre a covid-19 propôs suspender conflitos para auxiliar no combate à doença, sem se envolver no debate sobre a pandemia propriamente dita ${ }^{33}$.

Não se pode ignorar a atuação e a presença permanente, absolutamente fundamental e comprometida da OMS ao longo desta crise. Porém, como fica claro na história recente, é vital avaliar se a agência tem apoio político, recursos financeiros e materiais, estrutura operacional e instrumentos institucionais/regulatórios suficientes para ser capaz de lidar com o atual desafio, que só pode ser enfrentado com compromisso, empenho e investimento irrestritos do Conselho de Segurança e da Assembleia Geral da ONU, que em última análise são o conjunto de seus Estados-membros. No caso do Brasil, tais reflexões são especialmente importantes dadas as ações, posições e manifestações dos representantes do país em relação à pandemia, que destoam ou mesmo se contrapõem às recomendações da OMS, sem que se vislumbre nesse comportamento qualquer fundamentação científica ou ética.

Outro aspecto que prevalece em meio aos esforços internacionais em busca da vacina contra o 
coronavírus é o modelo big science ${ }^{34,35}$. Nele, o interesse particular de nações, coadunado aos de empresas nos setores de biotecnologia e medicamentos - a exemplo da parceria entre o governo norte-americano e uma das maiores empresas farmacêuticas do mundo ${ }^{36}-$, acaba por privilegiar esforços isolados e independentes que concentram o conhecimento e a propriedade intelectual/industrial, em última análise assegurando o poder geopolítico sobre o futuro. Assim, ao menos em parte, essas questões talvez expliquem as críticas desarrazoadas do governo dos Estados Unidos à OMS e sua decisão de retirar apoio político e financeiro à organização ${ }^{37}$.

Ainda que resultados pontuais de esforços em busca da vacina possam ser compartilhados, o conhecimento desenvolvido, que permitiria enfrentar situações parecidas no futuro, não o será. Superar o atual modelo de ciência hermética e protecionista praticado por países que centralizam o desenvolvimento de setores como o de biotecnologia é desafio que antecede a covid-19 e que permanecerá. Enfrentá-lo poderia nos fazer chegar a uma próxima pandemia em situação melhor.

A citada aliança do governo norte-americano com uma grande farmacêutica promete uma vacina para conter o vírus - mas promessas semelhantes já foram feitas anteriormente, como a respeito da cloroquina e hidroxicloroquina, adotadas pelo governo brasileiro sem restrições. No entanto, a realidade atual reclama por responsabilidade partilhada e cooperação entre as nações, abdicando de ações isoladas, da competição para obter recursos materiais e insumos e de uma volta precipitada, rodeada de incertezas, à normalidade de mercado. Talvez este seja o momento de pensar alternativas, que, por mais desafiadoras que sejam, devem ser debatidas.

Poderia, por exemplo, o Conselho de Segurança da ONU estabelecer um lockdown global? Isso interromperia a pandemia mais rapidamente e com menores danos à economia? Os efeitos residuais em médio e longo prazo seriam menores? O sacrifício feito por tantos países e tantas pessoas poderia ser atenuado nos próximos meses e anos? Com efeito, o espírito de responsabilidade partiIhada pelo qual o tempo presente clama exige ações movidas por precaução inteligente, e não pelo progresso econômico a todo custo.

\section{Conflito de valores}

Apesar das divergências, pode-se dizer que na maioria das sociedades contemporâneas prevaleceu o entendimento de que sem democracia não há condições mínimas para que os direitos humanos solucionem dissensões ${ }^{38}$. Tal compreensão, no entanto, tem sido desafiada por decisões tomadas no contexto de adversidades da pandemia de covid-19, a qual, à medida que avança, faz eclodir uma série de conflitos relacionados à realidade econômica, política e ideológica de cada país e grupo de interesse.

No Brasil, o ambiente institucional e social vem se tornando cada vez mais conflituoso, com ameaças quase diárias à democracia e um distanciamento perigoso entre governo e população, com desenlaces que se afastam de referenciais minimamente éticos. Temas altamente sensíveis, como meio ambiente, economia, reforma previdenciária e trabalhista, povos indígenas, direitos humanos e educação, entre outros, são tratados simultaneamente à gestão da pandemia. Essa concomitância tira o foco da tarefa de salvar vidas, dispersando esforços e orçamento, desfocando a opinião pública e impedindo um consenso mínimo sobre qual é a maior ameaça no momento e como enfrentar os demais problemas.

No aparente caos em que o país se vê merguIhado, duas situações parecem claras: profunda crise ética afeta o país e impede o controle da covid-19, e está em curso agenda político-econômica que desconsidera os efeitos da pandemia em termos humanitários. Sob a perspectiva desta última - cujo sucesso é também uma tragédia -, não há conflitos éticos, apenas prioridades distintas. Além disso, para essa agenda não se trata de considerar se a crise de saúde de fato produzirá o caos que se anuncia sobre a economia, mas apenas de aproveitar a ocasião para justificar as pautas geopolíticas e econômicas em curso.

A ética cede ao autoritarismo econômico e ao sectarismo político, desafiando a vida no presente e no futuro ${ }^{4}$. Neste cenário tétrico, convém pensar um imperativo ético subjacente à civilização moderna, tecnológica, de modo a conceber ações construtivas para a possibilidade de vida humana na Terra. De forma responsável, tal matriz ética - convergente com a dignidade da vida - deveria se sobrepor ao modelo econômico e político.

\section{A ética na tomada de decisão}

O persistente (e falso) dilema entre salvar a economia ou salvar vidas evidencia não apenas diferenças de perspectiva sobre como enfrentar a covid-19, mas também diferenças de valores e fundamentos éticos. Na saúde, a equidade é um dos mais importantes critérios éticos para definir ações prementes com base em necessidades e mensurar 
a real dimensão da preocupação e prioridades dos governos no que se refere aos grupos mais vulneráveis. Em termos mais pragmáticos, a equidade é referencial para comparar, por exemplo, a extensão de pacotes de ajuda financeira em relação a outros recursos que compõem o orçamento público.

No Brasil, a ajuda destinada a complementar a renda dos mais vulneráveis durante a pandemia proposta pelo Governo com o valor de R\$200 por mês por beneficiário, mas aprovada no Congresso Nacional com o valor de R\$ 600 por mês - foi estimada inicialmente em $\mathrm{R} \$ 14,4$ bilhões ${ }^{39}$. Ao mesmo tempo, de todo o orçamento da União para 2020, na ordem de $\mathrm{R} \$ 3,6$ trilhões $^{40}$, aproximadamente $40 \%$ está comprometido com o pagamento dos serviços da dívida externa (juros e amortização) ${ }^{41}$. Somente a dívida externa, sem considerar a interna, soma impagáveis US\$ 570 bilhões.

Para ilustrar, em 2019 foram pagos $R \$ 1,037$ trilhão, algo em torno de $\mathrm{R} \$ 2,8$ bilhões por dia. Usando por base esses dados de 2019 (um paralelo precário, apenas para exemplificar), o atual pacote de ajuda aos mais vulneráveis poderia ser coberto com apenas cinco dias de pagamento dos serviços da dívida. Ainda que o volume total da ajuda humanitária alcance cifras maiores até o fim da pandemia, esse aumento não chegará a mudar o quadro, a lógica ou as prioridades do orçamento público.

A prioridade dada ao pagamento dos serviços da dívida externa é traço comum entre países subdesenvolvidos ou em desenvolvimento, a que Jonas ${ }^{4}$ se refere como "condenados da Terra". Um efeito trágico desse cenário, como apontam Velji e Bryant, é a associação dívida-morte: quanto maior o pagamento de juros em função da dívida de uma nação, menor a expectativa média de vida dos cidadãos dessa mesma nação ${ }^{42}$.

Nesse sentido, de forma especialmente relevante para o momento atual, Cardoso e colaboradores advertem que um dos efeitos mais visíveis deste conjunto de circunstâncias diz respeito à equidade no acesso à saúde e à disponibilidade de recursos e meios para proteger as pessoas de cada país:

Um desses fatores é a rapidez com que, atualmente, eventos como as pandemias com impactos imediatos sobre a vida das populações e sobre a economia dos países podem ampliar seu escopo de incidência. Países de menor desenvolvimento e com grandes segmentos humanos vivendo em condições precárias não dispõem de sistemas de saúde capazes de arcar com impactos significativos desses eventos. Ainda que existam condições para remediação dos agravos provocados, o acesso a vacinas e medicamentos não é garantido aos países com capacidade de inovação e produção limitadas ou inexistentes, ainda que possam contornar as restrições colocadas por problemas de propriedade industrial ${ }^{43}$.

Embora o vírus não diferencie riqueza ou classe social, ricos e pobres não estão sujeitos aos riscos da mesma maneira nem terão as mesmas condições e possibilidades de enfrentar a pandemia. Alguns podem permanecer totalmente isolados do mundo, como se estivessem em ilhas particulares, durante $o$ tempo que for necessário, enquanto a maioria dos cidadãos não dispõe de um cômodo para se isolar, ou sequer tem casa. Enquanto para muitos não há leito em hospitais, alguns poucos podem ter UTI particulares montadas na própria residência.

A análise de Velji e Bryant parece absolutamente pertinente neste momento: sem comprometimento dos princípios éticos - direitos humanos e liberdade, justiça, adequação, equidade - é recusado ao cidadão global fraco e desfavorecido o acesso à educação, moradia, empregos e alimentos; ele é colocado em uma batalha desproporcional contra o cidadão privilegiado em um ambiente neoliberal $e$ altamente individualista ${ }^{44}$. Essa distância entre ricos e pobres no mundo produz situações muito diversas, algumas das quais, como a pandemia, parecem ser inevitavelmente trágicas.

Os refugiados, por exemplo, expulsos de seus territórios e à margem de qualquer sistema político-econômico, estão à mercê da ajuda humanitária que, dadas as dificuldades enfrentadas por todos os países para superar internamente a pandemia, devem tardar a chegar. Com efeito, em meio a situação como essa, não se trata de discutir o papel do Estado como mitigador da distância entre ricos e pobres - ainda que, em médio e longo prazos, essa seja uma necessidade e medida de justiça -, mas de reconhecer que é função do Estado garantir que tal distância não seja um fator de vantagem em luta desigual pela sobrevivência.

Outro aspecto que chama atenção diz respeito a manifestações públicas e decisões de autoridades de alguns países para minimizar a ameaça que representa a pandemia desconsiderando recomendações de isolamento social massivo e negando a realidade objetiva apontada por cientistas, autoridades sanitárias e pela própria OMS. Algumas autoridades retrocederam em seus posicionamentos, seja pela força dos acontecimentos, com centenas de mortes todos os dias, seja pelo instinto de sobrevivência política. Outras, como as do Brasil, persistem nessa aventura, 
em caso típico da "ignorância perigosa" de que trata Potter $^{5}$, e talvez como expressão dos totalitarismos modernos disfarçados de democracia, como descritos por Hannah Arendt ${ }^{45}$.

Esses totalitarismos contam com um exército de Eichmanns e Goebbels (hostis humani generis) dispostos a "cumprir seu dever" em atos e demonstrações "cívicas", panelaços, passeatas, carreatas, redes socais e tantos outros meios fornecidos pela moderna tecnologia de comunicação. Aliás, é interessante notar que os atos desse exército são sempre políticos e, como tal, expõem propósitos, têm consequências e, por isso mesmo, podem ser submetidos ao escrutínio da ética. Afinal, como aponta Arendt, a política não é um jardim de infância; em política, obediência e apoio são a mesma coisa ${ }^{46}$.

De todo modo, as vidas salvas ou perdidas, seja pela ação ou omissão daqueles que governam ou pelo apoio que recebem dos cidadãos, deverão ser contabilizadas na balança de responsabilidades de cada um. Essa é uma daquelas circunstâncias em que, como menciona Jonas, somos permanentemente confrontados com perspectivas finais cuja escolha positiva exige a mais alta sabedoria - uma situação definitivamente impossível para o homem em geral, pois ele não possui essa sabedoria, e para o homem contemporâneo em particular, que até mesmo nega a existência de valor absoluto e de verdade objetiva. Quando mais necessitamos de sabedoria é quando menos acreditamos nela ${ }^{47}$.

A respeito da chamada "imunização de rebanho", é preciso fazer mais algumas considerações. No caso brasileiro, esse debate parece revelar atuação velada de gestores públicos para promover a disseminação em larga escala do vírus. Entre outros fatores, parecem corroborar a adoção deliberada de tal política a ausência de testagem em massa de contaminados, a grande subnotificação, a demora crônica na emissão de laudos, a ineficiência dos sistemas de monitoramento de contagiados e a falta de articulação colaborativa e de integração da gestão nacional com as gestões estaduais. Um dos efeitos mais dramáticos desta política é o colapso do sistema de saúde e o esgotamento completo dos recursos para atendimento aos pacientes graves, forçando os profissionais de saúde a decidir quem terá acesso aos recursos de UTI.

Esse dilema ético tem sido largamente discutido, e critérios têm sido propostos para decidir quem terá acesso a leitos em caso de escassez, já que os princípios que costumeiramente norteiam emergências médicas e os respectivos códigos deontológicos não são suficientemente capazes de lidar com a situação provocada pela pandemia ${ }^{48-51}$. É preciso lembrar, porém, que este dilema tem origem em decisões político-institucionais que afetam e concorrem diretamente para a gravidade, amplitude e velocidade da propagação da covid-19, sobrecarregando as equipes de saúde, que passam a viver um cenário - com resultados trágicos - de instalação simultânea de problemas que poderiam ser evitados.

Diante da anomia do cenário sanitário atual, da absoluta falta de perspectivas em curto prazo e das ameaças que circundam o presente e o futuro, só há uma opção: seguir em frente. Mas por quais caminhos? As escolhas feitas agora vão determinar não apenas o número de vidas salvas, abandonadas e sacrificadas, mas também as condições para enfrentar as próximas pandemias e tragédias coletivas. A humanidade se vê pressionada pela ameaça do caos absoluto, mas o amanhã exige ação - mas quem tem essa responsabilidade, com base em que princípios e com que fundamentos?

\section{Considerações finais}

Nas palavras de Jonas, nesse cenário de tantas dificuldades e incertezas, os perigos que ameaçam o futuro modo de ser são, em geral, os mesmos que, em maior escala, ameaçam a existência; por isso, evitar os primeiros significa a fortiori evitar os outros ${ }^{52}$. Assim, o hiato entre a força da previsão e o poder do agir produz um novo problema ético. Reconhecer a ignorância torna-se, então, o outro lado da obrigação do saber ${ }^{53}$. Essa obrigação se impõe neste momento a todos os governantes e líderes mundiais, sendo problemático, portanto, que falte a algum deles a humildade necessária para ouvir e buscar conselhos fora de seus limitados círculos de interesse.

Lamentavelmente, manifestações de autoridades brasileiras têm mostrado que para alguns falta tanto sabedoria quanto a disposição de reconhecer sua ausência. Se o Conselho do Futuro - instituição que seria responsável por conciliar ciência e política, a partir do discernimento acerca do "conhecimento perigoso" -, proposto por Potter ${ }^{5}$, é uma alternativa, ou se, como aponta Jonas ${ }^{4}$, a humanidade terá que tomar as rédeas do próprio destino - o que significaria renunciar ao seu atual modo de existir para não ter que renunciar à própria existência - é questão premente. Como explica Jonas, esta é a perspectiva apocalíptica que se insere de forma previsível na dinâmica do atual curso da humanidade. Devemos compreender que estamos diante de uma dialética que só poderá ser enfrentada graças a uma escalada 
em termos de poder, e não com uma renúncia quietista ao poder ${ }^{54}$.

Há hoje o desafio de fazer escolhas que influenciarão o futuro: preservar a humanidade ou salvar a economia. Essa não é decisão semelhante à da bioética clínica, em que a virtude básica não é a prevenção de riscos, mas a avaliação prudente de benefícios, encargos e malefícios. Nessa concepção, o agir médico é dever, que no entanto não está relacionado ao futuro em sentido amplo, mas ao futuro imediato da vida em jogo, na forma do melhor resultado possível para determinado paciente.

A perspectiva da bioética clínica é substancialmente diferente da abordagem voltada à precaução, cujo princípio ordenador - que Jonas ${ }^{4}$ define como "princípio responsabilidade" - se apresenta como freio para o agir humano diante da antevisão de danos que a ação imprudente pode causar não apenas à sociedade humana do presente, mas também aos interesses e direitos de todas as vidas do futuro.

Na ótica da relação médico-paciente, o passado e o futuro contam apenas como elementos de diagnóstico e prognóstico para o paciente in casu. Apesar das imensas dificuldades e desafios de cada situação e do valor único e imensurável de cada vida, a ética aplicada nessas situações não ultrapassa o limite do arbitramento de cada caso, no restrito espaço e momento de sua ocorrência - mesmo porque a regra que salva um não raras vezes sacrifica outro. Apesar do papel do princípio da precaução na saúde individual, ele não é o seu balizador principal. Contudo, no contexto da pandemia, esse princípio tem outra dimensão.

Calendários delimitam o tempo histórico, mas mudanças de mentalidade estão além de divisas que tentam predeterminar a organização e a celebração dos ciclos. Entretanto, revoluções políticas, avanços científicos e a organização do sistema econômico vigente determinam o comportamento coletivo (terreno em que a humanidade se movimenta inconscientemente) e individual (campo específico e alienado da ampla mobilidade). Assim, é comum que mudanças de mentalidade tenham como marco eventos de grande proporção, como a Segunda Guerra Mundial. A pandemia de covid-19 parece ser um desses eventos, dados seus efeitos no campo científico e sua capacidade de tocar as bases do gênero humano, demonstrando a vulnerabilidade e a finitude da vida.

Trata-se de decidir se a humanidade será salva por princípio ou se apenas parte dela, como efeito colateral do objetivo último de salvar a economia esta, sim, abstração das necessidades humanas capturadas pelo egoísmo. Fomos capazes de criar um Projeto Manhattan para produzir armas de destruição em massa, mas não temos sido capazes de elaborar uma solução que salve em massa. Sem honestidade para perceber e admitir nossas falhas como espécie, não seremos capazes de corrigi-las. Precisamos entender que não se trata de salvar a humanidade de um vírus; em essência, trata-se de salvar a humanidade de si mesma. De outra forma, só podemos esperar que o que nos falta em sabedoria sobre em compaixão.

\section{Referências}

1. Jonas H. O princípio responsabilidade: ensaio de uma ética para a civilização tecnológica. Rio de Janeiro: Contraponto; 2006. p. 350-1.

2. Nordling L. "A ticking time bomb": scientists worry about coronavirus spread in Africa. Science [Internet]. 2020 [acesso 4 jun 2020]. Disponível: https://bit.ly/3ik78n7

3. WHO coronavirus disease (Covid-19) dashboard. World Health Organization [Internet]. 2020 [acesso 4 nov 2020]. Disponível: https://covid19.who.int/

4. Jonas H. Op. cit.

5. Potter VR. Bioética: ponte para o futuro. São Paulo: Loyola; 2016.

6. Zhu N, Zhang D, Wang W, Li X, Yang B, Song J et al. A novel coronavirus from patients with pneumonia in China, 2019. N Engl J Med [Internet]. 2020 [acesso 4 jun 2020];382:727-33. DOI: 10.1056/NEJMoa2001017

7. Andersen KG, Rambaut A, Lipkin WI, Holmes EC, Garry RF. The proximal origin of Sars-CoV-2. Nat Med [Internet]. 2020 [acesso 4 jun 2020];26:450-2. Disponível: https://go.nature.com/3n9YXOk

8. Zhou P, Yang X-L, Wang X-G, Hu B, Zhang L, Zhang W et al. A pneumonia outbreak associated with a new coronavirus of probable bat origin. Nat [Internet]. 2020 [acesso 4 jun 2020];579:270-3. DOI: $10.1038 / s 41586-020-2012-7$

9. Simmons G, Zmora P, Gierer S, Heurich A, Pöhlmann S. Proteolytic activation of the Sars-coronavirus spike protein: cutting enzymes at the cutting edge of antiviral research. Antiviral Res [Internet]. 2013 [acesso 4 jun 2020];100(3):605-14. DOI: 10.1016/j.antiviral.2013.09.028

10. Song W, Gui $M$, Wang X, Xiang Y. Cryo-EM structure of the Sars coronavirus spike glycoprotein in complex with its host cell receptor ACE2. PLoS Pathog [Internet]. 2018 [acesso 4 jun 2020];14(8):e1007236. DOI: $10.1371 /$ journal.ppat.1007236 
11. Coronaviridae Study Group of the International Committee on Taxonomy of Viruses. The species severe acute respiratory syndrome-related coronavirus: classifying $2019-n C o V$ and naming it Sars-CoV-2. Nat Microbiol [Internet]. 2020 [acesso 4 jun 2020];5:536-44. DOI: 10.1038/s41564-020-0695-z

12. Scripps Research Institute. Covid-19 coronavirus epidemic has a natural origin. ScienceDaily [Internet]. 2020 [acesso 4 jun 2020]. Disponível: https://bit.ly/3jpWqg8

13. Cui J, Li F, Shi Z-L. Origin and evolution of pathogenic coronaviruses. Nat Rev Microbiol [Internet]. 2019 [acesso 4 jun 2020];17:181-92. DOI: 10.1038/s41579-018-0118-9

14. Kupferschmidt K. Genome analyses help track coronavirus' moves. Science [Internet]. 2020 [acesso 4 jun 2020];367(6483):1176-7. DOI: 10.1126/science.367.6483.1176

15. Evans SW, Beal J, Berger K, Bleijs DA, Cagnetti A, Ceroni F et al. Embrace experimentation in biosecurity governance. Science [Internet]. 2020 [acesso 4 jun 2020];368(6487):138-40. DOI: 10.1126/science.aba2932

16. Service RF. NAS letter suggests 'normal breathing' can expel coronavirus. Science [Internet]. 2020 [acesso 4 jun 2020];368(6487):119. DOI: 10.1126/science.368.6487.119

17. Saplakoglu Y. Here's a look at the coronavirus's complicated journey through the body. Live Science [Internet]. 2020 [acesso 4 jun 2020]. Disponível: https://bit.ly/2Sd8zsW

18. Wadman M, Couzin-Frankel J, Kaiser J, Matacic C. How does coronavirus kill? Clinicians trace a ferocious rampage through the body, from brain to toes. Science [Internet]. 2020 [acesso 20 abr 2020]. Disponível: https://bit.ly/30oPXuh

19. Servick K. For survivors of severe Covid-19, beating the virus is just the beginning. Science [Internet]. 2020 [acesso 10 abr 2020]. Disponível: https://bit.ly/30krMNN

20. Servick K. Op. cit. § 7. Tradução livre.

21. Layne SP, Hyman JM, Morens DM, Taubenberger JK. New coronavirus outbreak: framing questions for pandemic prevention. Sci Transl Med [Internet]. 2020 [acesso 10 abr 2020];12(534):eabb1469. DOI: 10.1126/scitranslmed.abb1469

22. Saplakoglu Y. Asymptomatic people may be fueling the coronavirus spread. Live Science [Internet]. 2020 [acesso 6 abr 2020]. Disponível: https://bit.ly/34folpM

23. Lanese N. World coronavirus cases pass 1 million mark. Live Science [Internet]. 2020 [acesso 2 abr 2020]. Disponível: https://bit.ly/2HOtiRS

24. World Health Organization. Coronavirus disease 2019 (Covid-19): situation report 182 [Internet]. 2020 [acesso 1ㅇo out 2020]. Disponível: https://bit.ly/33kw7m3

25. Barros MPS. Caracterização genética de cepas de Yersinia pestis [tese] [Internet]. Recife: Universidade Federal de Pernambuco; 2012 [acesso 10 out 2020]. Disponível: https://bit.ly/3joSBbc

26. Barros MPS. Op. cit. p. 38-9.

27. OMS divulga lista de doenças e patógenos prioritários para pesquisa e desenvolvimento em 2018. Organização Pan-Americana de Saúde Brasil [Internet]. 2018 [acesso 26 fev 2020]. Disponível: https://bit.ly/34k5htm

28. World Health Organization. Report of the Ebola Interim Assessment Panel [Internet]. Geneva: World Health Organization; 2015 [acesso 26 fev 2020]. Disponível: https://bit.ly/349ft7S

29. World Health Organization. WHO Secretariat response to the Report of the Ebola Interim Assessment Panel [Internet]. Geneva: World Health Organization; 2015 [acesso 26 fev 2020]. Disponível: https://bit.ly/3nNgg7A

30. World Health Organization. Report of the Ebola Interim Assessment Panel. Op. cit. p. 5. Tradução livre.

31. World Health Organization. Report of the Ebola Interim Assessment Panel. Op. cit. p. 6. Tradução livre.

32. Ebola: ONU declara que surto "sem precedentes" é uma ameaça à paz e à segurança internacionais. Nações Unidas Brasil [Internet]. 2014 [acesso 26 fev 2020]. Disponível: https://bit.ly/31twLMN

33. Conselho de Segurança debate implementação de resolução sobre covid-19 e conflitos. ONU News [Internet]. Saúde; 9 set 2020 [acesso 30 nov 2020]. Disponível: https://bit.ly/37o0J60

34. Leite M. Retórica determinista no genoma humano. Sci Stud [Internet]. 2006 [acesso 26 fev 2020];4(3):421-52. DOI: 10.1590/S1678-31662006000300005

35. Frazier ME, Johnson GM, Thomassen DG, Oliver CE, Patrinos A. Realizing the potential of the genome revolution: the Genomes to Life program. Science [Internet]. 2003 [acesso 26 fev 2020];300(5617):290-3. DOI: 10.1126/science.1084566

36. Cohen J. The $\$ 1$ billion bet: pharma giant and U.S. government team up in all-out coronavirus vaccine push. Science [Internet]. 2020 [acesso 10 out 2020]. Disponível: https://bit.ly/2SeLtlt

37. Holland S, Nichols M. Trump anuncia rompimento dos Estados Unidos com a OMS. Agência Brasil Reuters [Internet]. Internacional; 29 maio 2020 [acesso 4 nov 2020]. Disponível: https://bit.ly/2HRqTGj

38. Bobbio N, Bovero M. Sociedade e Estado na política moderna. 4a ed. São Paulo: Brasiliense; 1986.

39. Piovesan E, Moraes G. Câmara aprova auxílio de $\mathrm{R} \$ 600$ para pessoas de baixa renda durante epidemia. Agência Câmara dos Deputados [Internet]. 2020 [acesso 1ㅇmaio 2020]. Disponível: https://bit.ly/3nbVTAD

40. Congresso aprova orçamento da União para 2020. Senado Notícias [Internet]. 2019 [acesso 10 maio 2020]. Disponível: https://bit.ly/2SeNvlB

41. Auditoria Cidadã da Dívida [Internet]. Brasília, 2020 [acesso 1 o maio 2020]. Disponível: https://bit.ly/33keyCw

42. Velji A, Bryant JH. Ética na saúde global. In: Markle WH, Fisher MA, Smego RA Jr. Compreendendo a saúde global. 2a ed. Porto Alegre: AMGH; 2015. p. 520-46. p. 529. 
43. Cardoso TAO, Navarro MBMA, Soares BEC, Tapajós AM. Biosseguridade e biossegurança: aplicabilidades da segurança biológica. Interciencia [Internet]. 2008 [acesso 10 maio 2020];33(8):561-8. p. 567. Disponível: https://bit.ly/3j5hsQa

44. Velji A, Bryant JH. Op. cit. p. 523.

45. Arendt $\mathrm{H}$. Eichmann em Jerusalém: um relato sobre a banalidade do mal. São Paulo: Companhia das Letras; 1999.

46. Arendt H. Op. cit. p. 302.

47. Jonas H. Op. cit. p. 63.

48. Vergaro M, Bertolini G, Giannini A, Gristina GR, Livigni S, Mistraletti G et al. Clinical ethics recommendations for the allocation of intensive care treatments in exceptional, resource-limited circumstances: the Italian perspective during the Covid-19 epidemic. Crit Care [Internet]. 2020 [acesso 20 abr 2020]:165. Disponível: https://bit.ly/33kl8sl

Barifouse R. Coronavírus: médicos podem ter de fazer "escolha de Sofia" por quem vai viver na Itália. BBC News Brasil [Internet]. 2020 [acesso 20 abr 2020]. Disponível: https://bbc.in/3n93rEp

50. Debert GG, Félix J. Dilema ético, os idosos e a metáfora da guerra. Folha de S.Paulo [Internet]. 2020 [acesso 19 abr 2020]. Disponível: https://bit.ly/2SiKKzK

51. Emanuel EJ, Persad G, Upshur R, Thome B, Parker M, Glickman A et al. Fair allocation of scarce medical resources in the time of Covid-19. N Engl J Med [Internet]. 2020 [acesso 10 out 2020];382(21):2049-55. DOI: 10.1056/NEJMsb2005114

52. Jonas H. Op. cit. p. 91.

53. Jonas H. Op. cit. p. 41.

54. Jonas H. Op. cit. p. 236.

\section{Participação dos autores}

Norton Nohama concebeu o estudo e redigiu o artigo. Jefferson Soares da Silva e Daiane Priscila Simão-Silva contribuíram na discussão e análise crítica do texto e atuaram na revisão final.

\section{Correspondência}

Daiane Priscila Simão-Silva - Rua Manoel Bandeira, 545, Conradinho CEP 85055-230. Guarapuava/PR, Brasil.

Norton Nohama - Mestre-nohama@ufpr.br

(iD) 0000-0003-0583-6723

Jefferson Soares da Silva - Doutor - jeffersonpdgg@gmail.com

(i) 0000-0002-1196-6391

Daiane Priscila Simão-Silva - Doutora - dpscientist@gmail.com

(iD) 0000-0002-1633-9899

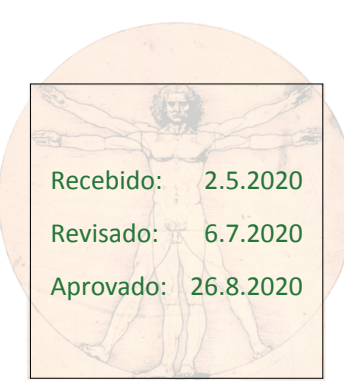

